\title{
DNA-Coated Gold Nanoparticles for the Detection of mRNA in Live Hydra Vulgaris Animals
}

Maria Moros, ${ }^{\dagger, \ddagger}$ Maria-Eleni Kyriazi, ${ }^{\dagger, \S}$ Afaf H. El-Sagheer, ${ }^{\perp, \| \odot}$ Tom Brown, ${ }^{\perp \odot}$ Claudia Tortiglione, ${ }^{*}$, and Antonios G. Kanaras*, ${ }^{,}, \#$

${ }^{\ddagger}$ Istituto di Scienze Applicate e Sistemi Intelligenti “E.Caianiello”, Consiglio Nazionale delle Ricerche, Pozzuoli 80078, Italy

${ }^{\S}$ Physics and Astronomy, Faculty of Physical Sciences and Engineering, and ${ }^{\#}$ Institute for Life Sciences, University of Southampton, Southampton SO171BJ, United Kingdom

${ }^{\perp}$ Department of Chemistry, University of Oxford, Chemistry Research Laboratory, 12 Mansfield Road, Oxford OX1 3TA, United Kingdom

"Chemistry Branch, Department of Science and Mathematics, Faculty of Petroleum and Mining Engineering, Suez University, Suez 43721, Egypt

Supporting Information

ABSTRACT: Advances in nanoparticle design have led to the development of nanoparticulate systems that can sense intracellular molecules, alter cellular processes, and release drugs to specific targets in vitro. In this work, we demonstrate that oligonucleotide-coated gold nanoparticles are suitable for the detection of mRNA in live Hydra vulgaris, a model organism, without affecting the animal's integrity. We specifically focus on the detection of Hymycl mRNA, which is responsible for the regulation of the balance between stem cell self-renewal and differentiation. Myc deregulation is found in more than half of human cancers, thus the ability to detect in vivo related mRNAs through innovative fluorescent systems is of outmost interest.

KEYWORDS: Hydra vulgaris, gold nanoparticles, oligonucleotides, mRNA detection, Hymyc1, nanoflares

\section{INTRODUCTION}

In recent years, gold nanoparticles (AuNPs) have been at the forefront of scientific research because of their attractive properties, which stem from their tunable shape, size, and ligand functionalization. ${ }^{1}$ In particular, spherical AuNPs have been extensively utilized because of their ease of synthesis as well as the ability to easily modify their surface with a variety of functional ligands using $\mathrm{Au}-\mathrm{S}$ chemistry. ${ }^{2-6}$ Among various types of functional ligands, AuNPs coated with synthetic oligonucleotides are very attractive for biomedical applications because they combine the unique properties of oligonucleotides, such as selectivity and specificity, with the optoelectronic properties of the gold core. Oligonucleotide-AuNP hybrids present enhanced colloidal stability, high cellular uptake without the requirement of cocarriers, and resistance to enzymatic degradation, advantages that have been explored for oligonucleotide detection as well as drug delivery in cells., ${ }^{2,-9}$

Specific detection is achieved by careful design considerations, which include the appropriate choice of oligonucleotides in terms of length and base content as well as the proper oligonucleotide density on the AuNP surface, with the aim on the one hand to prevent nanoprobe degradation by enzymes and on the other hand to retain oligonucleotide functionality and nanoparticle stability. ${ }^{10}$ Well-designed oligonucleotidecoated nanoparticles have been shown to be effective in the

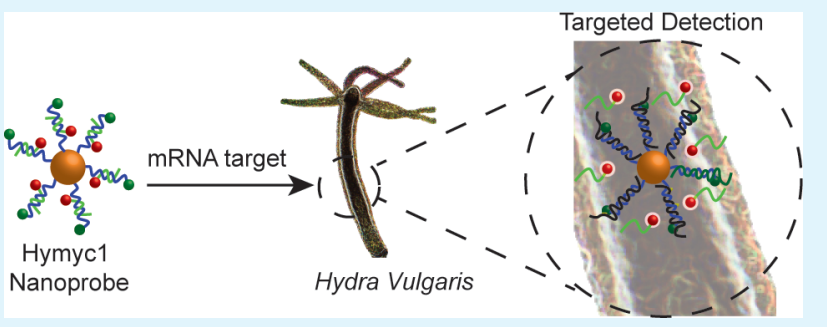

regulation of gene expression., ${ }^{2,11}$ For example, Rosi et al. demonstrated the use of oligonucleotide-coated nanoprobes for the downregulation of enhanced green fluorescent protein (EGFP). Upon uptake, a significant knockdown of the gene was observed in a mouse endothelial cell line $(\mathrm{C} 166) .{ }^{12}$ On the other hand, Giljohann et al. demonstrated the significant downregulation of luciferase in HeLa cells and Cutler et al. showed how such systems could silence the epidermal growth factor receptor (EGFR) in SCC12 cells. ${ }^{13,14}$ Furthermore, gene silencing has also been successfully demonstrated in vivo where Jensen et al. designed oligonucleotide-coated nanoprobes as a RNAi therapy of glioblastoma multiform (GBM) by targeting and knocking down bcl2L12 mRNA and the associated protein levels, which tend to be overexpressed in GBM. ${ }^{15}$ Following this study, Sita et al. demonstrated how the commonly administered drug for the treatment of GBM, temozolimide (TMZ), could be rendered more efficient by knocking down O6-methylguanine-DNA-methyltransferase (MGMT), a protein that hinders the drugs' mechanism of action. ${ }^{16}$ de la

Special Issue: Translational DNA Nanotechnology

Received: October 12, 2018

Accepted: November 26, 2018 
Fuente and co-workers also reported the use of siRNA nanoprobes to target tumor cells in lung cancer models via the downregulation of c-myc. ${ }^{17}$ They succeeded to induce RNAi both in vitro and in vivo, developing multiple strategies to bind siRNA to the gold nanoparticle core and achieving up to $80 \%$ of gene downregulation. ${ }^{18,19}$

Oligonucleotide-gold nanoparticle hybrids have also been used for the detection of intracellular targets including microRNA and mRNA. Mirkin and co-workers showed the utilization of such nanoprobes for the detection of survivin mRNA as well as the detection of genetic markers of circulating tumor cells (CTC) in human blood including mesenchymal markers such as twist, vimentin, and fibronectin and the epithelial marker E-cadherin. ${ }^{20,21}$ Similarly, Yang et al. used FRET oligonucleotide-coated gold nanoparticles to target tk1 mRNA, a target associated with cell division and tumor growth, in HepG2, MCF-7 and L02 cells, whereas Wright and co-workers made use of hairpin DNA-coated AuNPs for the detection of specific mRNA sequences for glyceraldehyde 3phosphate dehydrogenase (GAPDH) in Hep-2 cells and the Respiratory Syncytial Virus (RSV) in live RSV infected Hep-2 cells. $^{22,23}$ On the other hand, Zhou et al. used a hairpin system focusing on the detection of mdr1 mRNA, which has been associated with the prediction of multidrug resistance of tumor cells. $^{24}$ Moreover, research by our group has showed that oligonucleotide-coated AuNPs can be specifically designed to detect vimentin, desmocollin, and keratin 8 mRNAs, targets associated with the process of epithelial to mesenchymal transition (EMT) in live cells, whereas the detection of vimentin mRNA was also successfully demonstrated in models of wounded skin., ${ }^{9,25}$ This nanoparticle design has been extended beyond the confines of single target detection to achieve the simultaneous imaging of multiple mRNA targets. Prigodich et al. showed the simultaneous detection of two targets, survivin and actin, by monitoring two separate fluorescence outputs. ${ }^{26}$ Tang and co-workers have presented several studies focusing on multiplexed detection including the imaging of c-myc, tk1, and galnac-t mRNA in vitro in a number of different cell lines as well as the simultaneous fluorescence visualization of survivin and cyclin d1 mRNA in SK-BR-3 and MCF-10A cells. ${ }^{27-29}$ Furthermore, work by our group has also demonstrated how vimentin and keratin8 mRNA can be simultaneously detected via the use of AuNP dimers. ${ }^{8}$ Apart from mRNA, microRNA has also been detected using oligonucleotide-coated nanoprobes. Tu et al. demonstrated the detection of miR-122 in Huh7 cells using hairpin DNA coated AuNPs. This target constitutes $70 \%$ of the microRNA in the liver and its potential reduction has been associated with hepatocellular carcinoma. ${ }^{30}$ Furthermore, Huang et al. showed how two microRNA targets, miR-21 and miR-141 microRNA, could be simultaneously detected in live cancer cells including HeLa cells and LOVE- 1 cells. ${ }^{31}$

Although there is a significant amount of research focusing on the use of oligonucleotide-coated gold nanoparticles in in vitro systems there is less work associated with in vivo systems, which is highly important but experimentally more challenging.

In this work we demonstrate the targeted detection of mRNA using oligonucleotide-coated gold nanoparticles in the freshwater polyp Hydra vulgaris. Hydra is a small invertebrate classically used as model in developmental biology, which has also recently emerged as an amenable system to test the toxicity and bioactivity of novel functional biomaterials and nanodevices, $^{32-39}$ reducing ethical concerns and economic costs related to vertebrate experimentation. Hydra structural anatomy, which presents a tissue grade organization with no organs or biological fluids, allows the study of the interaction between any medium suspended compound and the entire body cell repertoire in a fast, simple, and reliable way. The polyp is structured as a hollow and transparent tube with a basal foot and a mouth (hypostome) surrounded by a ring of tentacles in the apical zone (see Figure S1). The body wall is composed by two epithelial layers, an ectoderm facing outward, and an endoderm facing the inner cavity, plus a limited number of differentiated cell types derived from interstitial stem cells, a fast cycling pool of cells located in the central part of the body column. ${ }^{40,41}$ These multipotent stem cells can occur singly (1s) or in clusters of $2,4,8$, and 16 cells $(2 s, 4 s, 8 s, 16 s)$ and undergo self-renewal or differentiation pathways into either nematocytes, the stinging cells characterizing the phylum, or neurons (sensory and ganglionic), secretory cells (gland cells and mucous cells), and gametes. ${ }^{42}$ Interstitial cells entering a nematocyte pathway undergo different cell divisions $(4 s, 8 s, 16 s)$, which results in nests of cells connected to each other by cytoplasmic bridges (nematoblasts) (see Figure S1). ${ }^{40}$ Among the numerous genes controlling the stem cell differentiation pathway, Hymyc 1 is specifically expressed in nests of dividing nematoblasts and gland cells, and it is involved in regulating the balance between stem cell self-renewal and differentiation $^{43-45}$

The well recognizable and defined expression pattern of Hymyc 1 in Hydra, its importance and the availability of its mRNA sequence prompted us to select this gene for the real time study of mRNA expression, in vivo. The gene belongs to the MYC proto-oncogene family (c-Myc, N-Myc, and L-Myc) of transcription factors controlling fundamental cellular processes including proliferation, growth, differentiation, metabolism, or apoptosis, conferring high translational value to our study. ${ }^{46-48}$ As myc deregulated expression occurs in the majority of human cancers, the availability of optimized detection methods may be of interest for the wide scientific community targeting $c-m y c$ for therapeutic purposes.

\section{EXPERIMENTAL SECTION}

Synthesis of $13.9 \pm 1.4 \mathrm{~nm}$ AuNPs. A solution of sodium tetrachloroaurate $(1 \mathrm{mM}, 100 \mathrm{~mL})$ was brought to the boil while stirring $(700 \mathrm{rpm})$. A solution of sodium citrate $(2 \% \mathrm{wt}, 5 \mathrm{~mL})$ was then injected into the gold solution. Following a solution color change, stirring $(700 \mathrm{rpm})$ was continued for further $15 \mathrm{~min}$. Once the reaction mixture reached room temperature, a solution of bissulfonatophenylphosphine (BSPP, $42 \mathrm{mg}$ in $2 \mathrm{~mL}$ of Milli-Q water) was added and the solution was left to stir overnight to ensure successful ligand replacement. The resulting BSPP-coated spherical AuNPs were passed through a $0.45(\mu \mathrm{m})$ Millipore filter to remove large aggregates and further purified by two rounds of centrifugation $(10000 \mathrm{rpm}, 20 \mathrm{~min})$. Purification was assisted via the gradual addition of a concentrated $\mathrm{NaCl}$ solution until a color change from red to blue was observed indicating particle precipitation. Synthesized AuNPs were finally redispersed in $3 \mathrm{~mL}$ of Milli-Q water and stored at $4{ }^{\circ} \mathrm{C}$.

Oligonucleotide Design. Sequences for Hymyc1-nanoprobes were designed based on Hymyc 1 gene sequence (GenBank Accession no. GQ856263). "Sense" strands were designed to have a length of 29 bases (target sequence including a polyA tail, see Table S1) with a GC content $<50 \%$. The "flare" strands were designed to have a melting temperature of $>40{ }^{\circ} \mathrm{C}$ and a length of 10 bases (see Table S1 for sequences). The Basic Local Assignment Search Tool (BLAST) tool was used to assess specificity and absence of off target sequences 
Synthesis of DNA-AuNPs for mRNA Detection. Synthesized AuNPs were modified with a shell of oligonucleotide "sense" strands designed to detect specific mRNA targets by adopting a salt-aging approach. Briefly, BSPP-coated AuNPs in water $(10 \mathrm{nM}, 1 \mathrm{~mL})$ were incubated with a solution of thiol-terminated oligonucleotide "sense" strands $(3 \mu \mathrm{M}, 1 \mathrm{~mL})$ and were left to shake for $24 \mathrm{~h}$. BSPP $(1 \mathrm{mg} / 20$ $\mu \mathrm{L}, 10 \mu \mathrm{L})$ was then added to the reaction mixture along with phosphate buffer (0.1 M, pH 7.4) and SDS (10\%) in order to achieve a final concentration of $0.01 \mathrm{M}$ and $1 \%$ of phosphate buffer and SDS, respectively. Successful oligonucleotide attachment was then achieved by gradually increasing the salt concentration. Six additions of $\mathrm{NaCl}$ ( $2 \mathrm{M})$ were performed over an $8 \mathrm{~h}$ period resulting in a final salt concentration of $0.3 \mathrm{M}$. Resulting oligonucleotide-coated AuNPs were purified by three rounds of centrifugation $(16400 \mathrm{rpm}, 20 \mathrm{~min})$ and stored at $4{ }^{\circ} \mathrm{C}$ in hybridization buffer $(5 \mathrm{mM}$ phosphate buffer, 80 $\mathrm{mM} \mathrm{NaCl}$ ).

Oligonucleotide "sense" strands were hybridized to their complementary "flare" strands by incubating a solution of oligonucleotide-coated "sense" strands $(40 \mathrm{nM}, 500 \mu \mathrm{L})$, with an excess of the complementary "flare" strand $(2.4 \mu \mathrm{M}, 500 \mu \mathrm{L})$. The solution was then heated to $65^{\circ} \mathrm{C}$ for 5 min followed by slow cooling to room temperature. The resulting probes were purified by two rounds of centrifugation (16400 rpm, $15 \mathrm{~min}$ ) and finally redispersed in phosphate buffer saline (PBS).

Culture of Animals. Hydra vulgaris was asexually cultured in Hydra medium $\left(1 \mathrm{mM} \mathrm{CaCl}_{2}\right.$ and $\left.0.1 \mathrm{mM} \mathrm{NaHCO}_{3}\right)$ at $\mathrm{pH}$ 7. The animals were kept at $18 \pm 1{ }^{\circ} \mathrm{C}$ and fed thrice a week with freshly hatched Artemia salina nauplii.

Toxicity Assay. Groups of 10 polyps were placed in a plastic multiwell and incubated with the AuNP probes $(10 \mathrm{nM}, 300 \mu \mathrm{L})$ for $24 \mathrm{~h}$. After washing the polyps with Hydra medium, the animals morphology was monitored using a stereomicroscope (Olympus SZXRFL2) and potential adverse effects were ranked assigning a numerical score as previously described. ${ }^{49}$

In Vivo Imaging. Groups of 10 polyps from homogeneous populations were selected for the experiments and incubated with AuNP probes $(10 \mathrm{nM}, 300 \mu \mathrm{L})$ for $3 \mathrm{~h}$ in Hydra medium. Animals were kept at $18{ }^{\circ} \mathrm{C}$ and protected from light. Following extensive washing, in vivo imaging was accomplished using an inverted fluorescence microscope (DMI 6000, Leica equipped with a Leica DFC360FX camera) or a Nikon Eclipse TIE. Images were acquired with a Cy3/TRITC filtercube $\left(\lambda_{\text {exc }}=552 \mathrm{~nm}, \lambda_{\mathrm{em}}=578 \mathrm{~nm}\right)$ and a FITC filtercube $\left(\lambda_{\text {exc }}=489 \mathrm{~nm}, \lambda_{\mathrm{em}}=508 \mathrm{~nm}\right)$. Images were taken under the same conditions of acquisition (light and exposure time) and analysis was performed using the LAS AS, Nikon TSI and ImageJ software systems. At least 4 biological replicas were carried out.

\section{RESULTS AND DISCUSSION}

Design and Synthesis of DNA-AuNPs. Scheme 1 demonstrates the main principle of mRNA detection using the DNA-coated nanoprobes. AuNPs were functionalized with thiol modified oligonucleotides, which have a terminal FAM dye (for simplicity these oligonucleotides are termed "sense" strands). A shorter oligonucleotide strand modified with a $\mathrm{Cy} 3$ dye (termed "flare" strand) was hybridized to the "sense" strand. Because of the close proximity of both dyes to the AuNP surface their fluorescence was suppressed by the gold core (OFF state). In the presence of the target mRNA complementary to the sense strand, the flare strand was released from the nanoparticle, leading to an increase in its fluorescence signature ( $\mathrm{Cy} 3, \mathrm{ON}$ state) that could be detected in live Hydra via fluorescence microscopy.

In this study, DNA-coated AuNPs were designed and synthesized for the targeted detection of Hymycl mRNA in Hydra vulgaris. By adopting a gradual salt-aging approach, we functionalized $14 \pm 1 \mathrm{~nm}$ AuNPs with a layer of "sense" oligonucleotide strands (see Figures S3 and S4 and Table S2
Scheme 1. Schematic Illustration of Nanoprobe Function ${ }^{a}$

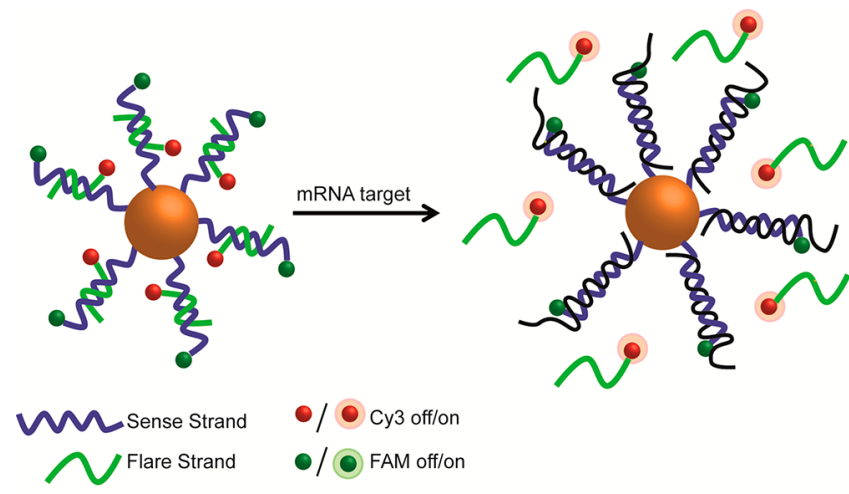

${ }^{a}$ When in close proximity to the AuNP surface, the fluorescence signal of the dyes on both the "sense" and "flare" strands is quenched. Upon mRNA detection, competitive hybridization leads to the displacement of the "flare" strand and the concomitant restoration of its fluorescence signature, which can be detected via fluorescence microscopy.

for qualitative characterization). All DNA-AuNPs were thoroughly characterized to determine successful "sense" strand attachment. Through degradation of the gold core and quantitative analysis of the oligonucleotide in solution it was determined that each AuNP was coated with approximately 110 oligonucleotide strands with no significant variation for nanoparticles incubated with other sequences (see Table S3 for quantitative characterization). For mRNA detection, each nanoprobe consisted of approximately $60 \times$ "flare" strands as shown in Table S4, where hybridization was also assessed via fluorescence melting analysis as seen in Figure S5.

Hydra polyps were incubated with three types of nanoprobes. The first batch was designed to detect the Hymycl mRNA (Hymycl nanoprobe), the second batch was designed with a scramble sequence (scramble nanoprobe) that does not detect any mRNA in Hydra (negative control), and the third batch was designed to detect all intracellular mRNA (positive control). The positive control (gmRNA nanoprobes) was designed to display a poly $\mathrm{T}$ "sense" and polyA "flare" strand capable of detecting all mature mRNA via their characteristic polyA tail (see Table S1 for detailed sequences). Scheme 2 shows the strategy of our experiment. Upon incubation and uptake of the Hymycl nanoprobes in live animals, the presence of the specific mRNA would result in the targeted displacement of the "flare" strand. On the other hand, in the case of the scramble nanoprobe, the absence of the target mRNA would result in the lack of displacement of the "flare" strand, which would remain bound to its complementary "sense" strand.

Prior to the experiment, an assessment of toxicity was performed by incubating living polyps with the nanoprobes for $24 \mathrm{~h}$. The induction of putative morphological damages was assessed by assigning numerical scores to progressive morphological alteration. ${ }^{50}$ The score ranges from 0 , where the polyp is disintegrated to 10 , where the polyps demonstrate an extended body and tentacles. Our research showed that none of the nanoprobes used throughout this study caused evident morphological changes after a $24 \mathrm{~h}$ incubation period, where all the polyp morphological scores were equal to 10 . The high biocompatibility of the gold nanoprobes found in this study is in line with previous reports, which demonstrated that 
Scheme 2. Schematic Illustration of the Process of mRNA Detection in $\mathrm{Hydra}^{a}$
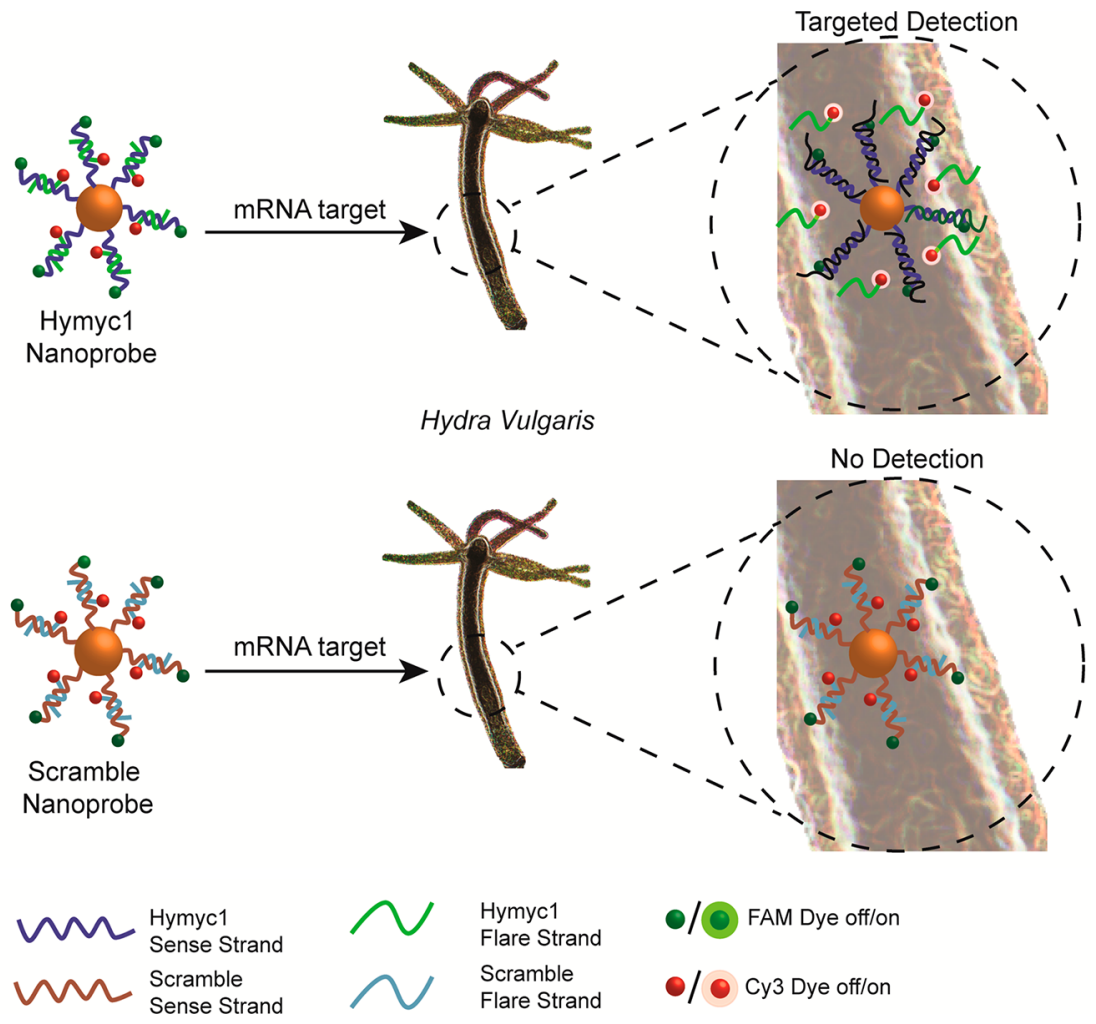

${ }^{a}$ Animals were incubated with nanoprobes designed with a sequence either to specifically detect Hymycl mRNA (Hymyc1 nanoprobes) or that does not detect any mRNA (scramble nanoprobes). Only in the presence of the target mRNA is the "flare" strand released and the fluorescence of the $\mathrm{Cy} 3$ dye restored.

AuNPs are not toxic to Hydra even at higher concentrations and longer incubation times. ${ }^{18,51}$

Detection of Hymyc1 mRNA in Hydra. Figure 1 shows that after $3 \mathrm{~h}$ of incubation, a red fluorescence signal was observed in animals treated with the nanoprobes that detect Hymycl mRNA, but not in those treated with scramblenanoprobes. The signal was located mainly in the animal's body column, as expected since Hymycl mRNA is expressed in the cells of the gastric region (see Figure S1a for a full image of the animal taken with an optical microscope) and it is absent in head and tentacles (see Figure S2b). On the other hand, when incubated with general mRNA nanoprobes (gmRNA nanoprobes) capable of detecting all mRNA, a fluorescence signal was located throughout the animals' body including the head and tentacles (see Figure S2c). ${ }^{43}$

As seen in Figure $1 \mathrm{~A}$, when incubated with the nanoprobes that detect Hymyc1 mRNA, Hydra showed a strong fluorescence signal in the body column due to the release of the Cy3-labeled "flare" strand. On the other hand, Figure 1D shows that upon incubation of live animals with scramble nanoprobes, no signal corresponding to "flare" release was detectable. The faint fluorescence detected in Figure 1D was comparable to the autofluorescence signal detected from live animals prior to treatment with nanoprobes (Figure 1G). Furthermore, bright field images were also acquired and presented in Figure 1C, F, and I showing the part of the Hydra body being analyzed. This data confirmed the specificity of the system toward the accurate detection of an mRNA target. In each case, the absence of a fluorescence signal from the FAMmodified "sense" strand (Figure $1 \mathrm{~B}, \mathrm{E}$, and $\mathrm{H}$ ) confirmed that

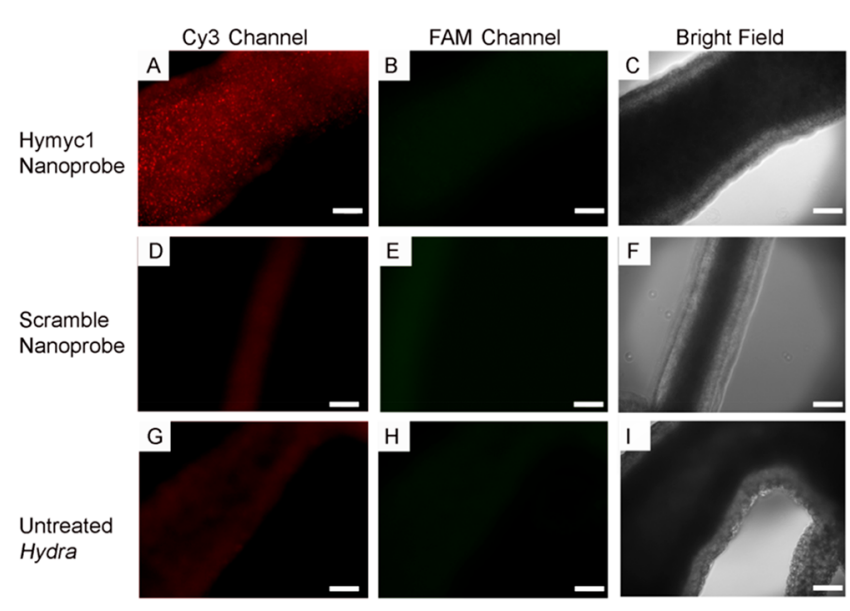

Figure 1. Fluorescence microscopy images of the (A, D, G) Cy3 and (B, E, H) FAM channel of the gastric region of live Hydra incubated with $(\mathrm{A}-\mathrm{C})$ nanoprobes specific for the detection of Hymycl mRNA, (D-F) nanoprobes designed with a scramble sequence that does not detect any mRNA, and (G-I) Hydra not treated with nanoprobes. Color guide for the different channels: Red ( $\mathrm{Cy} 3)$, fluorescence signal corresponding to "flare" strand release. Green (FAM), fluorescence signal corresponding to "sense" strand release. Bright-field images of the animal are also presented in C, F, and I. Scale bars are $100 \mu \mathrm{m}$.

the "sense" strand remained on the nanoparticle surface without any signs of degradation in live tissue.

Figures 2 and 3 show images at higher magnification after incubation with $\mathrm{Hymycl}$ nanoprobes. As seen, the Hymycl 


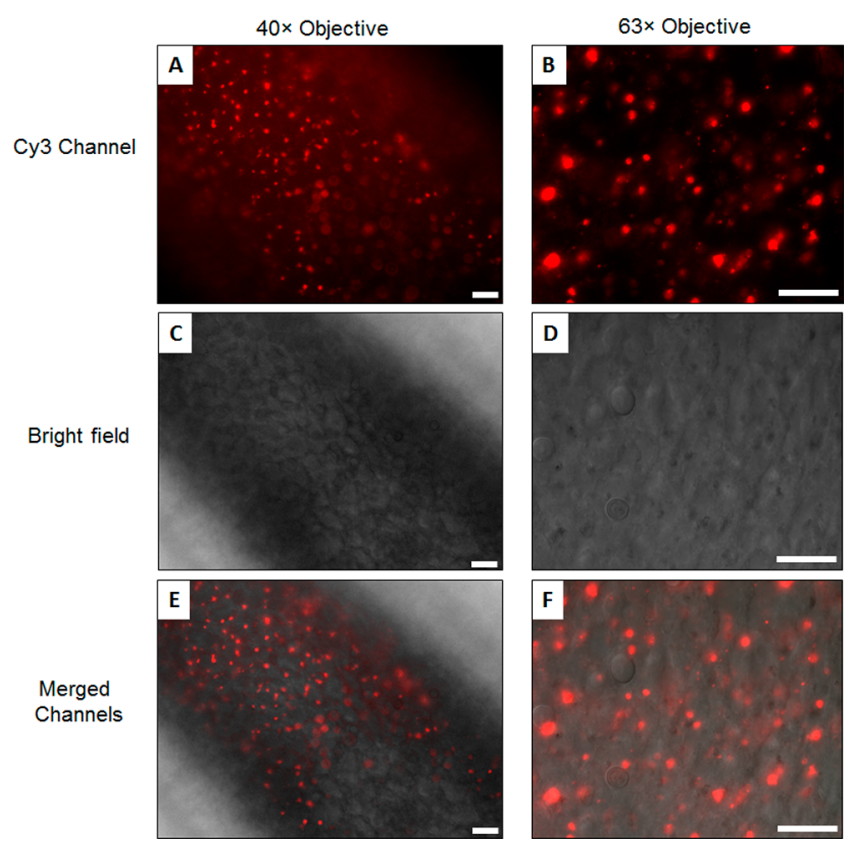

Figure 2. Higher-magnification fluorescence microscopy images of the gastric region of live Hydra incubated with nanoprobes specific for the detection of Hymycl mRNA. The (A, B) Cy3, (C, D) bright-field and $(E, F)$ merged channels are presented for images taken using a (A, C, E) $40 \times$ and (B, D, F) $63 \times$ oil immersion objective. Scale bars are $25 \mu \mathrm{m}$.
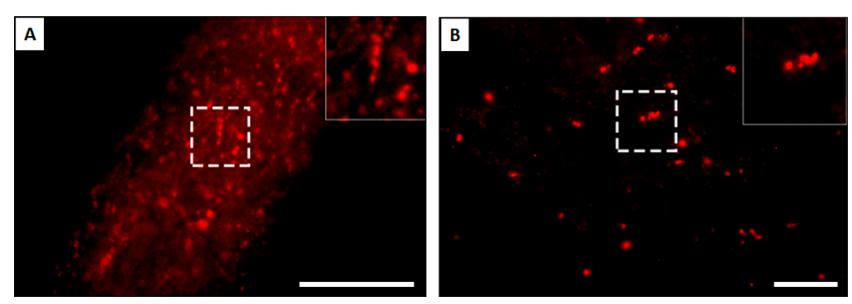

Figure 3. Fluorescence microscopy images of the gastric region of live Hydra incubated with nanoprobes specific for the detection of Hymyc1 mRNA where nests of nematoblasts are seen and enlarged in the right corner of the pictures. (A) Images obtained using a $10 \times$ objective. (B) Images obtained using a $20 \times$ objective. Color guide: Red (Cy3), fluorescence signal corresponding to "flare" strand release. Scale bars are $100 \mu \mathrm{m}$.

nanoprobe produced a precise and recognizable fluorescent pattern due to single and nests of interstitial stem cells, mirroring endogenous Hymycl mRNA. Similar expression pattern has been described by whole-mount in situ hybridization using digoxigenin-labeled Hymyc1 RNA probes. ${ }^{4-45}$

Overall, these results demonstrate the possibility to specifically detect Hymycl mRNA in real time in vivo. The fact that within the animal body column no green fluorescence could be observed means that the "sense" strand was not displaced from the AuNP surface. On the other hand, the detection of mRNA in the cells means cytoplasmic delivery of AuNPs, where the mRNA is present. Although the mechanism of uptake of these nanoprobes has not been investigated yet, it has been already described that $14 \mathrm{~nm}$ spherical AuNPs bearing siRNA can directly penetrate the plasma membrane of ectodermal cells just after $30 \mathrm{~min}$ of incubation with Hydra. ${ }^{52}$ Avoiding the classical endocytic pathways, AuNPs were able to deliver the siRNA and induce a gene downregulation. ${ }^{18}$ The
AuNPs were also found on the membrane of interstitial cells, where Hymycl should be expressed.

\section{CONCLUSIONS}

In summary, we have shown that small amounts of DNAcoated AuNPs as used within this study are not toxic to Hydra and they can be employed to detect specific mRNAs in these animals. Here, we successfully detected the presence of the Hymycl mRNA using the corresponding oligonucleotide nanoprobes without any signs of nanoprobe degradation. On the other hand, no fluorescence was detected when scramble sequence nanoprobes were used. Our results demonstrate the possibility of using DNA-coated AuNPs as a fast and reliable tool to qualitatively monitor the presence or not of specific mRNA targets in Hydra animals. Because of the key role played by the MYC transcription factor family in cell and animal biology, the choice of $m y c$ as target gene for our methodology confers high translational impact to our results. In vertebrates the MYC protein controls a variety of processes spanning from cell cycle, to apoptosis and the balance between stem cell self-renewal/differentiation, thus the availability of safe and efficient tools to monitor in real time its expression levels may open the path to a wide use of these DNA-coated AuNPs as novel investigation tools in stem cell and cancer biology and in any physiological and pathological contexts demanding mRNA detection tools. The strength of our proposed approach relies on the fast kinetics of mRNA detection. Previous studies have relied on in situ hybridization to assess mRNA biodistribution, a technique that is costly and time-consuming as it relies on the in vitro cloning of doublestranded DNA encoding for the gene of interest, synthesis of digoxigenin-labeled riboprobe (antisense strand) and finally on the hybridization of this riboprobe with the endogenous sense mRNA in fixed tissue. Furthermore, that technique is prone to signal saturation and the generation of high signal backgrounds. Our work represents an important advance for the fast and accurate detection of mRNA targets within an in vivo environment and it can pave the way for the broader exploitation of oligonucleotide coated gold nanoparticles in clinical applications, as a rapid method for the reliable assessment of mRNA expression in living tissue.

\section{ASSOCIATED CONTENT}

\section{S Supporting Information}

The Supporting Information is available free of charge on the ACS Publications website at DOI: 10.1021/acsami.8b17846.

Detailed DNA-coated AuNP characterization such as UV-vis spectra, gel electrophoresis images, and zeta potential measurements; complementary fluorescence images and experimental results of live Hydra incubated with DNA-coated nanoprobes (PDF)

\section{AUTHOR INFORMATION}

\section{Corresponding Authors}

*Email: a.kanaras@soton.ac.uk.

*Email: claudia.tortiglione@cnr.it.

ORCID

Afaf H. El-Sagheer: 0000-0001-8706-1292

Tom Brown: 0000-0002-6538-3036

Antonios G. Kanaras: 0000-0002-9847-6706 


\section{Author Contributions}

${ }^{\dagger}$ M.M. and M.-E.K contributed equally.

\section{Notes}

The authors declare no competing financial interest.

The raw data for this manuscript is available at https://doi. org/10.5258/SOTON/D0727.

\section{ACKNOWLEDGMENTS}

A.K. and M.-E.K. thank the Leverhulme Trust (ref RPG-2015005) and BBSRC (Grant BB/P017711/1) for funding of this project. M.M. acknowledges the European Union's Horizon 2020 research and innovation programme (Marie SkłodowskaCurie grant agreement 660228).

\section{REFERENCES}

(1) Kelly, K. L.; Coronado, E.; Zhao, L. L.; Schatz, G. C. The Optical Properties of Metal Nanoparticles: The Influence of Size, Shape, and Dielectric Environment. J. Phys. Chem. B 2003, 107, 668677.

(2) Cutler, J. I.; Auyeung, E.; Mirkin, C. A. Spherical Nucleic Acids. J. Am. Chem. Soc. 2012, 134, 1376-1391.

(3) Giljohann, D. A.; Seferos, D. S.; Daniel, W. L.; Massich, M. D.; Patel, P. C.; Mirkin, C. A. Gold Nanoparticles for Biology and Medicine. Angew. Chem., Int. Ed. 2010, 49, 3280-3294.

(4) Heuer-Jungemann, A.; Harimech, P. K.; Brown, T.; Kanaras, A. G. Gold Nanoparticles and Fluorescently-Labelled DNA as a Platform for Biological Sensing. Nanoscale 2013, 5, 9503-9510.

(5) Bartczak, D.; Muskens, O. L.; Sanchez-Elsner, T.; Kanaras, A. G.; Millar, T. M. Manipulation of in Vitro Angiogenesis Using PeptideCoated Gold Nanoparticles. ACS Nano 2013, 7, 5628-5636.

(6) El-Sayed, I. H.; Huang, X. H.; El-Sayed, M. A. Surface Plasmon Resonance Scattering and Absorption of Anti-EGFR Antibody Conjugated Gold Nanoparticles in Cancer Diagnostics: Applications in Oral Cancer. Nano Lett. 2005, 5, 829-834.

(7) Lytton-Jean, A. K. R.; Mirkin, C. A. A Thermodynamic Investigation Into the Binding Properties of DNA Functionalized Gold Nanoparticle Probes and Molecular Fluorophore Probes. J. Am. Chem. Soc. 2005, 127, 12754-12755.

(8) Kyriazi, M. E.; Giust, D.; El-Sagheer, A. H.; Lackie, P. M.; Muskens, O. L.; Brown, T.; Kanaras, A. G. Multiplexed mRNA Sensing and Combinatorial-Targeted Drug Delivery Using DNA-Gold Nanoparticle Dimers. ACS Nano 2018, 12, 3333-3340.

(9) Heuer-Jungemann, A.; El-Sagheer, A. H.; Lackie, P. M.; Brown, T.; Kanaras, A. G. Selective Killing of Cells Triggered by Their mRNA Signature in the Presence of Smart Nanoparticles. Nanoscale 2016, 8, 16857-16861.

(10) Barnaby, S. N.; Perelman, G. A.; Kohlstedt, K. L.; Chinen, A. B.; Schatz, G. C.; Mirkin, C. A. Design Considerations for RNA Spherical Nucleic Acids (SNAs). Bioconjugate Chem. 2016, 27, 21242131.

(11) Ding, Y.; Jiang, Z. W.; Saha, K.; Kim, C. S.; Kim, S. T.; Landis, R. F.; Rotello, V. M. Gold Nanoparticles for Nucleic Acid Delivery. Mol. Ther. 2014, 22, 1075-1083.

(12) Rosi, N. L.; Giljohann, D. A.; Thaxton, C. S.; Lytton-Jean, A. K. R.; Han, M. S.; Mirkin, C. A. Oligonucleotide-Modified Gold Nanoparticles for Intracellular Gene Regulation. Science 2006, 312, 1027-1030.

(13) Giljohann, D. A.; Seferos, D. S.; Prigodich, A. E.; Patel, P. C.; Mirkin, C. A. Gene Regulation with Polyvalent siRNA-Nanoparticle Conjugates. J. Am. Chem. Soc. 2009, 131, 2072-2073.

(14) Cutler, J. I.; Zhang, K.; Zheng, D.; Auyeung, E.; Prigodich, A. E.; Mirkin, C. A. Polyvalent Nucleic Acid Nanostructures. J. Am. Chem. Soc. 2011, 133, 9254-9257.

(15) Jensen, S. A.; Day, E. S.; Ko, C. H.; Hurley, L. A.; Luciano, J. P.; Kouri, F. M.; Merkel, T. J.; Luthi, A. J.; Patel, P. C.; Cutler, J. I.; Daniel, W. L.; Scott, A. W.; Rotz, M. W.; Meade, T. J.; Giljohann, D. A.; Mirkin, C. A.; Stegh, A. H. Spherical Nucleic Acid Nanoparticle
Conjugates as an RNAi-Based Therapy for Glioblastoma. Sci. Transl. Med. 2013, 5, 209ra152.

(16) Sita, T. L.; Kouri, F. M.; Hurley, L. A.; Merkel, T. J.; Chalastanis, A.; May, J. L.; Ghelfi, S. T.; Cole, L. E.; Cayton, T. C.; Barnaby, S. N.; Sprangers, A. J.; Savalia, N.; James, C. D.; Lee, A.; Mirkin, C. A.; Stegh, A. H. Dual Bioluminescence and Near-Infrared Fluorescence Monitoring to Evaluate Spherical Nucleic Acid Nanoconjugate Activity In Vivo. Proc. Natl. Acad. Sci. U. S. A. 2017, 114, 4129-4134.

(17) Conde, J.; Tian, F. R.; Hernandez, Y.; Bao, C. C.; Cui, D. X.; Janssen, K. P.; Ibarra, M. R.; Baptista, P. V.; Stoeger, T.; de la Fuente, J. M. In Vivo Tumor Targeting via Nanoparticle-Mediated Therapeutic siRNA Coupled to Inflammatory Response in Lung Cancer Mouse Models. Biomaterials 2013, 34, 7744-7753.

(18) Conde, J.; Ambrosone, A.; Sanz, V.; Hernandez, Y.; Marchesano, V.; Tian, F.; Child, H.; Berry, C. C.; Ibarra, M. R.; Baptista, P. V.; Tortiglione, C.; de la Fuente, J. M. Design of Multifunctional Gold Nanoparticles for In Vitro and In Vivo Gene Silencing. ACS Nano 2012, 6, 8316-8324.

(19) Conde, J.; Ambrosone, A.; Hernandez, Y.; Tian, F. R.; McCully, M.; Berry, C. C.; Baptista, P. V.; Tortiglione, C.; de la Fuente, J. M. 15 Years on siRNA Delivery: Beyond the State-of-the-Art on Inorganic Nanoparticles for RNAi Therapeutics. Nano Today 2015, 10, 421450.

(20) Halo, T. L.; McMahon, K. M.; Angeloni, N. L.; Xu, Y.; Wang, W.; Chinen, A. B.; Malin, D.; Strekalova, E.; Cryns, V. L.; Cheng, C.; Mirkin, C. A.; Thaxton, C. S. NanoFlares for the Detection, Isolation, and Culture of Live Tumor Cells from Human Blood. Proc. Natl. Acad. Sci. U. S. A. 2014, 111, 17104-17109.

(21) Seferos, D. S.; Giljohann, D. A.; Hill, H. D.; Prigodich, A. E.; Mirkin, C. A. Nano-flares: Probes for Transfection and mRNA Detection in Living Cells. J. Am. Chem. Soc. 2007, 129, 15477-15479.

(22) Yang, Y. J.; Huang, J.; Yang, X. H.; Quan, K.; Wang, H.; Ying, L.; Xie, N. L.; Ou, M.; Wang, K. M. FRET Nanoflares for Intracellular mRNA Detection: Avoiding False Positive Signals and Minimizing Effects of System Fluctuations. J. Am. Chem. Soc. 2015, 137, 83408343.

(23) Jayagopal, A.; Halfpenny, K. C.; Perez, J. W.; Wright, D. W. Hairpin DNA-Functionalized Gold Colloids for the Imaging of mRNA in Live Cells. J. Am. Chem. Soc. 2010, 132, 9789-9796.

(24) Zhou, Q. M.; Qian, Z. Y.; Gu, Y. Q. Detection of MDR1 mRNA Expression With Optimized Gold Nanoparticle Beacon. In Conference on Reporters, Markers, Dyes, Nanoparticles, and Molecular Probes for Biomedical Applications VIII; SPIE, 2016.

(25) Vilela, P.; Heuer-Jungemann, A.; El-Sagheer, A.; Brown, T.; Muskens, O. L.; Smyth, N. R.; Kanaras, A. G. Sensing of Vimentin mRNA in 2D and 3D Models of Wounded Skin Using DNA-Coated Gold Nanoparticles. Small 2018, 14, 1703489.

(26) Prigodich, A. E.; Randeria, P. S.; Briley, W. E.; Kim, N. J.; Daniel, W. L.; Giljohann, D. A.; Mirkin, C. A. Multiplexed Nanoflares: mRNA Detection in Live Cells. Anal. Chem. 2012, 84, 2062-2066.

(27) Li, N.; Chang, C.; Pan, W.; Tang, B. A Multicolor Nanoprobe for Detection and Imaging of Tumor-Related mRNAs in Living Cells. Angew. Chem., Int. Ed. 2012, 51, 7426-7430.

(28) Qiao, G. M.; Gao, Y.; Li, N.; Yu, Z. Z.; Zhuo, L. H.; Tang, B. Simultaneous Detection of Intracellular Tumor mRNA with Bi-Color Imaging Based on a Gold Nanoparticle/Molecular Beacon. Chem. Eur. J. 2011, 17, 11210-11215.

(29) Pan, W.; Zhang, T.; Yang, H.; Diao, W.; Li, N.; Tang, B. Multiplexed Detection and Imaging of Intracellular mRNAs Using a Four-Color Nanoprobe. Anal. Chem. 2013, 85, 10581-10588.

(30) Tu, Y. Q.; Wu, P.; Zhang, H.; Cai, C. X. Fluorescence Quenching of Gold Nanoparticles Integrating With a ConformationSwitched Hairpin Oligonucleotide Probe for microRNA Detection. Chem. Commun. 2012, 48, 10718-10720.

(31) Li, J.; Huang, J.; Yang, X.; Yang, Y.; Quan, K.; Xie, N.; Wu, Y.; Ma, C.; Wang, K. Two-Color-Based Nanoflares for Multiplexed MicroRNAs Imaging in Live Cells. Nanotheranostics 2018, 2, 96-105. 
(32) Ambrosone, A.; Mattera, L.; Marchesano, V.; Quarta, A.; Susha, A. S.; Tino, A.; Rogach, A. L.; Tortiglione, C. Mechanisms Underlying Toxicity Induced by CdTe Quantum Dots Determined in an Invertebrate Model Organism. Biomaterials 2012, 33, 1991-2000.

(33) Tortiglione, C.; Antognazza, M. R.; Tino, A.; Bossio, C.; Marchesano, V.; Bauduin, A.; Zangoli, M.; Morata, S. V.; Lanzani, G. Semiconducting Polymers are Light Nanotransducers in Eyeless Animals. Sci. Adv. 2017, 3, e1601699.

(34) Ambrosone, A.; Roopin, M.; Pelaz, B.; Abdelmonem, A. M.; Ackermann, L. M.; Mattera, L.; Allocca, M.; Tino, A.; Klapper, M.; Parak, W. J.; Levy, O.; Tortiglione, C. Dissecting Common and Divergent Molecular Pathways Elicited by CdSe/ZnS Quantum Dots in Freshwater and Marine Sentinel Invertebrates. Nanotoxicology 2017, 11, 289-303.

(35) Marchesano, V.; Hernandez, Y.; Salvenmoser, W.; Ambrosone, A.; Tino, A.; Hobmayer, B.; M de la Fuente, J.; Tortiglione, C. Imaging Inward and Outward Trafficking of Gold Nanoparticles in Whole Animals. ACS Nano 2013, 7, 2431-2442.

(36) Moros, M.; Ambrosone, A.; Stepien, G.; Fabozzi, F.; Marchesano, V.; Castaldi, A.; Tino, A.; de la Fuente, J. M.; Tortiglione, C. Deciphering Intracellular Events Triggered by Mild Magnetic Hyperthermia In Vitro and In Vivo. Nanomedicine 2015, 10, $2167-2183$.

(37) Ambrosone, A.; Marchesano, V.; Carregal-Romero, S.; Intartaglia, D.; Parak, W. J.; Tortiglione, C. Control of Wnt/betaCatenin Signaling Pathway In Vivo via Light Responsive Capsules. ACS Nano 2016, 10, 4828-4834.

(38) Malvindi, M. A.; Carbone, L.; Quarta, A.; Tino, A.; Manna, L.; Pellegrino, T.; Tortiglione, C. Rod-Shaped Nanocrystals Elicit Neuronal Activity In Vivo. Small 2008, 4, 1747-1755.

(39) Tortiglione, C., An Ancient Model Organism to Test In Vivo Novel Functional Nanocrystals In Biomedical Engineering: From Theory to Application; Fazel-Rezai, R., Ed.; InTech: 2011; Vol. Biomedical Engineering: from theory to application, pp 225-252.

(40) Bode, H. R. The Interstitial Cell Lineage of Hydra: a Stem Cell System That Arose Early in Evolution. J. Cell Sci. 1996, 109, 11551164.

(41) Hobmayer, B.; Jenewein, M.; Eder, D.; Eder, M.-K.; Glasauer, S.; Gufler, S.; Hartl, M.; Salvenmoser, W. Stemness in Hydra - A Current Perspective. Int. J. Dev. Biol. 2012, 56, 509-517.

(42) David, C. N.; Gierer, A. Cell Cycle Kinetics and Development of Hydra Attenuata. III. Nerve and Nematocyte Differentiation. J. Cell Sci. 1974, 16, 359-375.

(43) Hartl, M.; Mitterstiller, A. M.; Valovka, T.; Breuker, K.; Hobmayer, B.; Bister, K. Stem Cell-Specific Activation of an Ancestral myc Protooncogene with Conserved Basic Functions in the Early Metazoan Hydra. Proc. Natl. Acad. Sci. U. S. A. 2010, 107, 40514056.

(44) Ambrosone, A.; Marchesano, V.; Tino, A.; Hobmayer, B.; Tortiglione, C. Hymyc1 Downregulation Promotes Stem Cell Proliferation in Hydra Vulgaris. PLoS One 2012, 7, e30660.

(45) Hartl, M.; Glasauer, S.; Valovka, T.; Breuker, K.; Hobmayer, B.; Bister, K. Hydra myc2, a Unique Pre-Bilaterian Member of the Myc Gene Family, is Activated in Cell Proliferation and Gametogenesis. Biol. Open 2014, 3, 397-407.

(46) Dang, C. V.; O’Donnell, K. A.; Zeller, K. I.; Nguyen, T.; Osthus, R. C.; Li, F. The c-Myc Target Gene Network. Semin. Cancer Biol. 2006, 16, 253-64.

(47) Amati, B.; Brooks, M. W.; Levy, N.; Littlewood, T. D.; Evan, G. I.; Land, H. Oncogenic Activity of the c-Myc Protein Requires Dimerization with Max. Cell 1993, 72, 233-245.

(48) Eilers, M.; Eisenman, R. N. Myc's Broad Reach. Genes Dev. 2008, 22 (20), 2755-2766.

(49) Wilby, O. K.; Tesh, J. M. The Hydra Assay as an Early Screen for Teratogenic Potential. Toxicol. In Vitro 1990, 4, 582-583.

(50) Wilby, O. K.; Tesh, J. M. The Hydra Assay as a Nearly Screen for Teratogenic Potential. Toxicol. In Vitro 1990, 4, 582-583.
(51) Ambrosone, A.; Pino, P. D.; Marchesano, V.; Parak, W. J.; de la Fuente, J. M.; Tortiglione, C. Gold Nanoprisms for Photothermal Cell Ablation In Vivo. Nanomedicine 2014, 9, 1913-1922.

(52) Marchesano, V.; Hernandez, Y.; Salvenmoser, W.; Ambrosone, A.; Tino, A.; Hobmayer, B.; de la Fuente, J. M.; Tortiglione, C. Imaging Inward and Outward Trafficking of Gold Nanoparticles in Whole Animals. ACS Nano 2013, 7, 2431-2442. 